\title{
Comparison of human bronchiolar smooth muscle responsiveness in vitro with histological signs of inflammation
}

\author{
JOHAN C DE JONGSTE, HARRY MONS, ROEL VAN STRIK, IVAN L BONTA, \\ KAREL F KERREBIJN
}

From the Departments of Paediatric Respiratory Diseases, Pharmacology and Biostatistics, Erasmus Universityo Rotterdam/Sophia Children's Hospital, PO Box 70029, 3000 LL Rotterdam, The Netherlands

ABSTRACT A study was carried out to test the hypothesis that chronic inflammation is associate $\vec{\phi}$ with increased sensitivity or contractility of human airway smooth muscle. Bronchiolar strips fron 30 patients, 12 of whom had chronic bronchitis, were examined in the organ bath for their responses to histamine, methacholine, and leukotriene (LT) $\mathrm{C}_{4}$. The same airways were also studied histologe ically and small airway disease was quantified by subjective grading of the degree of inflammatory cell infiltration, smooth muscle hypertrophy, fibrosis, and goblet cell hyperplasia. The degree oo small airway disease varied widely among patients both with and without chronic bronchitis. Mut tiple regression analysis failed to show increased sensitivity $\left(-\log \mathrm{EC}_{50}\right)$ to histamine, metha? choline, or $\mathrm{LTC}_{4}$ in relation to small airway disease. In contrast, the only significant correlations found were between a decreased $-\log \mathrm{EC}_{50}$ to histamine and methacholine and an increased sma airway disease score. Contractile responses $\left(\mathrm{T}_{\max }\right)$ to histamine and methacholine in periphera airways tended to be higher in patients with chronic bronchitis than in those without. $T_{\max }$ was not related to small airway disease scores. These results suggest that chronic airway inflammation does not cause in vitro hyperresponsiveness of human small airway smooth muscle.

\section{Introduction}

Clinical observations have led to the view that airway inflammation may be an important modulator of non-specific bronchial responsiveness in patients with asthma or chronic bronchitis and even in normal individuals. $^{1-5}$ Moreover, we recently found increased histamine responsiveness in isolated peripheral airways from patients with chronic bronchitis and airflow obstruction. ${ }^{6}$ The mechanisms by which inflammation could enhance bronchial responsiveness are not clear. Few studies have examined the responsiveness of isolated human airways in relation to the histological appearance of the bronchial tissue, and these studies have shown no relation between the degree of airway disease and function. ${ }^{78}$

In the present study we measured the functional responses to pharmacological stimulation of isolated

\footnotetext{
Address for reprint requests: Dr J C de Jongste, Sophia Children's Hospital, Department of Paediatric Respiratory Diseases, PO Box 70029, 3000 LL Rotterdam, The Netherlands.

peripheral airways from patients with and without chronic bronchitis or airflow obstruction (or both) and quantified various histological aspects of smaly airway disease in the same preparations by means 0 . a subjective grading method. Functional data weri related to histological findings to determine whethe? inflamed peripheral airways are more responsive io vitro than non-inflamed airways.

\section{Methods}

\section{PATIENTS}

Thirty patients who underwent lobectomy on pneumonectomy -29 for bronchial carcinoma anf one for carcinoid tumour-were included in the study. All patients had lung function tests before surgery, including inspiratory vital capacity (VC) an $\$$ forced expiratory volume in one second (FEV if before and after $10 \mathrm{mg}$ nebulised isoprenaling Chronic bronchitis was diagnosed according to the Medical Research Council criteria of cough an phlegm production for more than two years and more than three months in a year. ${ }^{9}$ Subjects were classifiee 
as "normal" when they reported no respiratory symptoms, apart from recent symptoms caused by their tumour, and had normal lung function with an $\mathrm{FEV}_{1} / \mathrm{VC}$ of at least $70 \%$. In 11 patients bronchial responsiveness was measured in vivo before surgery. Nebulised histamine was administered via a Wiesbadener Doppel Inhalator in doubling concentrations, and the provocative concentration that caused a $20 \%$ fall in $\mathrm{FEV}_{1}$ from baseline $\left(\mathrm{PC}_{20}\right.$ FEV $_{1}$ ) was calculated. ${ }^{10}$ The study protocol was approved by the ethical committee of the University Hospital.

\section{IN VITRO STUDIES}

Immediately after surgical resection a macroscopically normal piece of lung tissue was collected in ice cold Krebs-Henseleit buffer (composition in $\mathrm{mmol} / \mathrm{l}: \mathrm{NaCl} 118, \mathrm{KCl} 4,7, \mathrm{CaCl}_{2} 2,5, \mathrm{MgSO}_{4} 1,2$, $\mathrm{KH}_{2} \mathrm{PO}_{4} 1,2, \mathrm{NaHCO}_{3} 25$, glucose 5, 55), aerated with $5 \%$ carbon dioxide and $95 \%$ oxygen, and rapidly transported to the laboratory. Bronchiolar strips (10th-13th generation) were dissected, stored overnight, and studied isometrically, with Grass FTO3D transducers, in a $10 \mathrm{ml}$ organ bath containing aerated Krebs-Henseleit buffer at $37^{\circ} \mathrm{C}$, as described previously. ${ }^{11} \mathrm{~A}$ baseline tension of $500 \mathrm{mg}$ was applied. Histamine hydrochloride, methacholine bromide (Janssen pharmaceuticals, Belgium), and leukotriene (LT) $\mathrm{C}_{4}$ (a gift from Dr J Rokach, Merck Frosst, Canada) were used as contracting agents, and three cumulative concentration-response curves were made in succession on a single bronchiolar strip from each patient. The sequence of the agonists was determined by a random digits table. From each concentrationresponse curve the $\mathrm{EC}_{50}$ value (the molar agonist concentration that produced $50 \%$ of the maximal effect on a given strip) was derived as a measure of smooth muscle sensitivity. We have previously shown that for $\mathrm{EC}_{50}$ measurements this procedure does not lead to interactions between these three agonists. ${ }^{12}$ The maximal force ( $T_{\max }$, contractility) developed by a strip was calculated only for the first concentrationresponse curve on each strip because interactions occur with $T_{\max }$ when agonists are applied successively. ${ }^{12}$

\section{HISTOLOGY}

After dissection of the bronchiolar strips a proximal segment was removed, fixated in formalin, and processed for histological examination. We used a simplified version of Cosio's subjective grading method, ${ }^{13}$ adapted for bronchiolar strips, to assess the severity of small airway disease. The items scored were (1) inflammatory cell infiltration, (2) smooth muscle hypertrophy, (3) goblet cell hyperplasia, and (4) fibrosis. Each item was assigned a score (0-3) by comparison with pictorial reference standards, 0 representing the normal picture and 1-3 reflecting increasing degrees of abnormality (fig 1 ). The total small airway disease score was the sum of scores for the four items, so 12 was the maximum attainable score. The validity of the scoring system was confirmed in a preliminary study (the mean (SEM) kappa coefficients for within and between observer agreement were $0.77(0.07)$ and $0.66(0.12))$.

\section{STATISTICAL ANALYSIS}

Data for patients with and without chronic bronchitis were compared by means of Student's $t$ test (two tailed). For each agonist the $\mathrm{EC}_{50}$ and $\mathrm{T}_{\max }$ values of 30 strips from 30 patients were related to the total small airway disease score by linear regression analysis. The relation between $\mathrm{EC}_{50}$ and $\mathrm{T}_{\max }$ values and the four separate small airway disease items was examined by multiple regression analysis. The significance of the regression was determined by analysis of variance and the $F$ test $(\alpha=0.05)$.

\section{Results}

Of the 30 patients, 12 had chronic bronchitis as defined, and 18 reported no cough or phlegm. None of the patients had a history of asthma. The clinical findings are summarised in table 1. Eight of the 18 subjects without symptoms of chronic bronchitis had airflow obstruction $\left(\mathrm{FEV}_{1} / \mathrm{VC}<70 \%\right)$. Although this subgroup had a higher mean age and may have had airway obstruction or compression by tumour, we analysed the results for this subgroup separately.

Current cigarette smoking was reported by eight of the 12 patients with symptoms of chronic bronchitis and by five of those without symptoms. Three subjects without chronic bronchitis smoked a pipe or cigars. Only one subject had never smoked; all others had ceased smoking at least two years previously (table 1).

The response to histamine in vivo was measured in eight patients without and three with chronic bronchitis. The $\mathrm{PC}_{20} \mathrm{FEV}_{1}$ was greater than $64 \mathrm{mg} / \mathrm{ml}$ in all patients except one of the three with chronic bronchitis $(32 \mathrm{mg} / \mathrm{ml})$ (table 1). A wide range of small airway disease was found in patients both with and without chronic bronchitis. Severe disease was slightly more common in chronic bronchitis, but group mean small airway disease scores did not differ significantly (table 2). Current cigarette smoking was not associated with the small airway disease score within groups. The scoring system did not take account of the composition of the inflammatory cells in the airway wall, but most were neutrophilic granulocytes and mononuclear cells (fig 1); eosinophils were rare.

The results of the in vitro experiments are sum- 


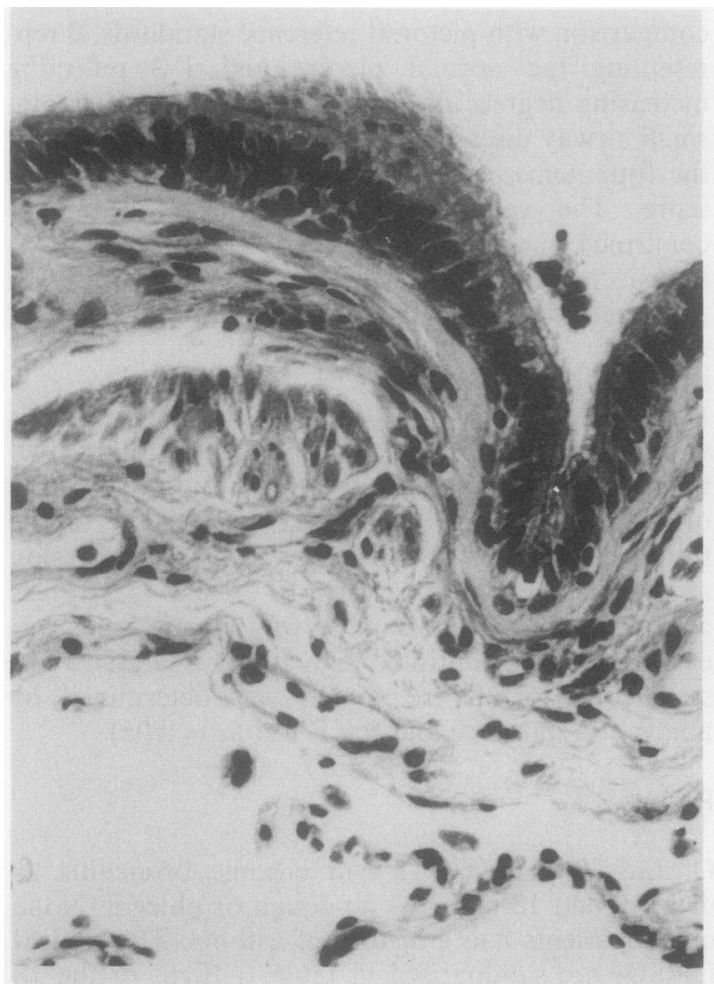

(a)

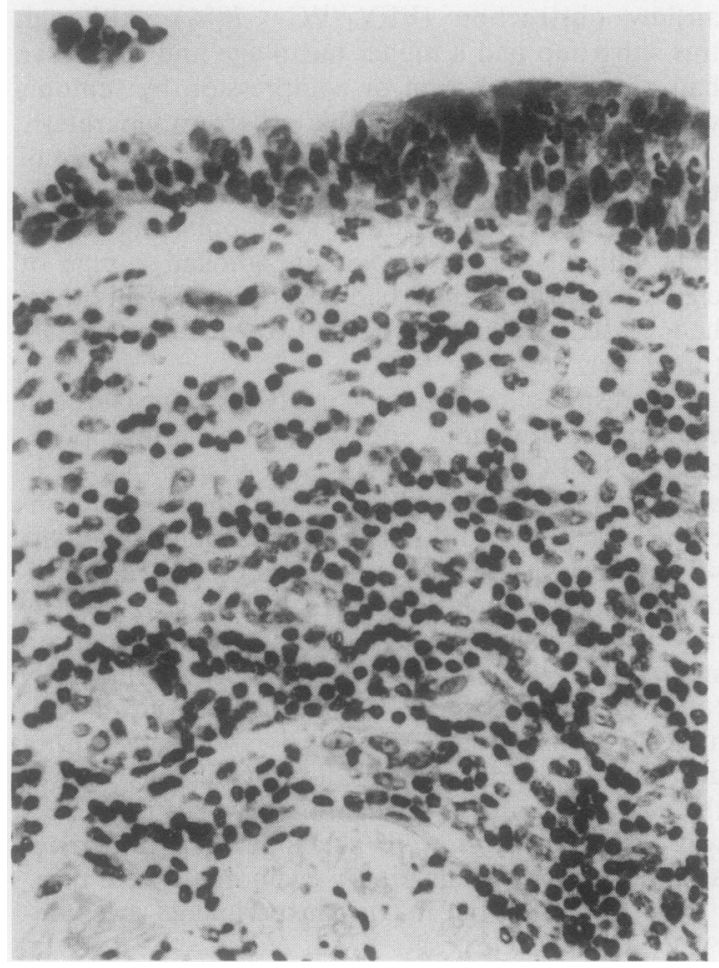

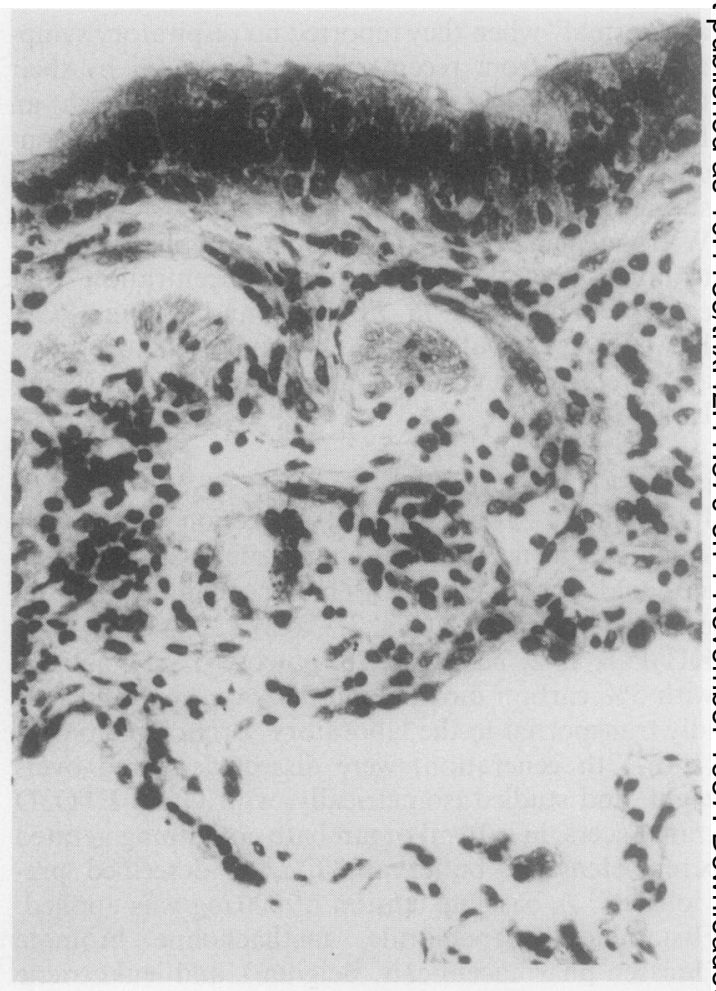

(b)

Fig 1 Photomicrographs showing various degrees of inflammatory cell infiltration in bronchiolar strips a $b$, and are increasingly abnormal pictures of inflammatory cell accumulation corresponding to cellular infiltration scores $1,2=$ and 3 respectively. (May-Grünwald-Giesma.) G 
Table 1 Characteristics of the patients (mean (SEM) values)

\begin{tabular}{|c|c|c|c|}
\hline & $\begin{array}{l}\text { No chronic bronchitis, } \\
\text { no airflow obstruction } \\
(n=10)\end{array}$ & $\begin{array}{l}\text { No chronic bronchitis, } \\
\text { airflow obstruction } \\
(n=8)\end{array}$ & $\begin{array}{l}\text { Chronic bronchitis, } \\
\text { airflow obstruction } \\
(\mathrm{n}=12)\end{array}$ \\
\hline Age (years) & $49(5)$ & $65(3)$ & $55(5)$ \\
\hline 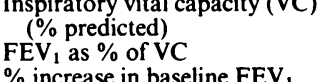 & $\begin{array}{r}105(4) \\
77(2)\end{array}$ & $\begin{aligned} 108(7) \\
59(3)\end{aligned}$ & $\begin{array}{l}97(5) \\
55(4)\end{array}$ \\
\hline $\begin{array}{l}\text { \% increase in baseline } \mathrm{FEV}_{1} \\
\text { after isoprenaline }\end{array}$ & $1(1)$ & $4(1)$ & $10(3)$ \\
\hline $\begin{array}{l}\text { Smoking habit }(n) \\
\text { Current smoker } \\
\text { Ex-smoker }(>2 \text { years }) \\
\text { Never smoked }\end{array}$ & $\begin{array}{l}4 \\
5 \\
1\end{array}$ & $\begin{array}{l}4 \\
4 \\
0\end{array}$ & $\begin{array}{l}8 \\
4 \\
0\end{array}$ \\
\hline $\begin{array}{l}\text { Response to inhaled histamine } \\
\left(\mathrm{PC}_{20} \mathrm{FEV}_{1}, \mathrm{mg} / \mathrm{ml}\right)\end{array}$ & $>64(n=6)$ & $>64(n=2)$ & $\begin{array}{r}>64(\mathrm{n}=2) \\
\quad 32(\mathrm{n}=1)\end{array}$ \\
\hline
\end{tabular}

Table 2 Histological findings (mean (SEM) values)

\begin{tabular}{|c|c|c|c|}
\hline & \multicolumn{3}{|c|}{ Small airways disease scores* } \\
\hline & $\begin{array}{l}\text { No chronic bronchitis, } \\
\text { no airflow obstruction } \\
(n=10)\end{array}$ & $\begin{array}{l}\text { No chronic bronchitis, } \\
\text { airflow obstruction } \\
(n=8)\end{array}$ & $\begin{array}{l}\text { Chronic bronchitis, } \\
\text { airflow obstruction } \\
(\mathrm{n}=12)\end{array}$ \\
\hline $\begin{array}{l}\text { Small airway disease feature } \\
\text { Cellular infiltration } \\
\text { Muscle hypertrophy } \\
\text { Fibrosis } \\
\text { Goblet cell hyperplasia } \\
\text { Total small airways disease score }\end{array}$ & $\begin{array}{l}0.9(0.4) \\
0.9(0.3) \\
1.2(0.2) \\
0.7(0.3) \\
3.7(0.9)\end{array}$ & $\begin{array}{l}0.5(0.3) \\
0.4(0.2) \\
1.9(0.2) \\
1.0(0.3) \\
3.8(0.5)\end{array}$ & $\begin{array}{l}0.7(0.2) \\
0.7(0.2) \\
1.8(0.3) \\
1.3(0.3) \\
4.5(0.7)\end{array}$ \\
\hline
\end{tabular}

*No significant differences existed between the groups.

marised in table 3 . The $-\log \mathrm{EC}_{50}$ values of methacholine, histamine, and $\mathrm{LTC}_{4}$ were similar in patients with and without chronic bronchitis or airflow obstruction. As a consequence of the randomisation procedure, histamine was applied as the first drug to 15 of the 30 airway preparations, and methacholine and $\mathrm{LTC}_{4}$ to nine and six strips respectively. Because of the relatively large variation of $T_{\max }$ within subjects, ${ }^{12}$ no conclusions about possible differences in $T_{\max }$ between groups of patients can be drawn from the small numbers of observations. There was, however, a tendency for histamine and methacholine $T_{\max }$ to be higher in airways from patients with chronic bronchitis and airflow obstruction (table 3). Because no differences were found in small airway disease scores or $\mathrm{EC}_{50}$ values between groups of patients, the relation between small airway disease and $\mathrm{EC}_{50}$ was analysed on the total population. The methacholine $-\log \mathrm{EC}_{50}$ showed a weak but significant negative correlation with total small airway disease scores $(p<0.05)$ - that is, severely diseased airways tended to be less sensitive to methacholine. No relation between histamine or LTC4 $\mathrm{EC}_{50}$ and total small airway disease scores was found (fig 2). Multiple regression analysis showed that inflammatory cell infiltration was the only single variable that correlated negatively with both methacholine $-\log \mathrm{EC}_{50}$ $(\mathrm{p}<0.05)$ and histamine $-\log \mathrm{EC}_{50} \quad(\mathrm{p}<0.05)$ (fig 3). $T_{\max }$ values for histamine, methacholine, and LTC $_{4}$ were not related to the severity of small airway disease.

\section{Discussion}

Our results indicate that small airway disease and, in particular, inflammatory cell infiltration of the airway wall in patients with and without chronic bronchitis is not associated with increased sensitivity or contractility of small airway smooth muscle to histamine, methacholine, and $\mathrm{LTC}_{4}$ in vitro. Infiltration of inflammatory cells was negatively correlated with histamine and methacholine sensitivity, which was the opposite of what we expected. In accordance with our earlier findings, ${ }^{6}$ histamine $T_{\max }$ tended to be higher in airways from patients with chronic bronchitis and airflow obstruction than in airways from normal subjects. In this study mean $T_{\max }$ for methacholine was also higher in the patients with chronic bronchitis. Statistical analysis was not carried out because of the small numbers of observations and the large intrinsic variation in $T_{\max } \cdot{ }^{11}$ There was no correlation between $T_{\max }$ and small airway disease scores. Airway inflammation scores were determined before tissue was stored and possibly the storage procedure and 
Table 3 Results of in vitro concentration-response studies

\begin{tabular}{|c|c|c|c|c|}
\hline & & $\begin{array}{l}\text { No chronic bronchitis, } \\
\text { no airflow obstruction } \\
(n=10)\end{array}$ & $\begin{array}{l}\text { No chronic bronchitis, } \\
\text { airflow obstruction } \\
(n=8)\end{array}$ & $\begin{array}{l}\text { Chronic bronchitis, } \\
\text { airflow obstruction } \\
(\mathrm{n}=12)\end{array}$ \\
\hline Histamine & $\frac{-}{T_{\max } \dagger}+\log \mathrm{EC}_{50} *$ & $\begin{array}{l}5 \cdot 77(0.09) \\
51(8)[4]\end{array}$ & $\begin{array}{l}5.96(0.07) \\
73(21)[5]\end{array}$ & $\begin{array}{l}5 \cdot 79(0 \cdot 11) \\
113(21)[6]\end{array}$ \\
\hline Methacholine & $\frac{-\log E C_{50} *}{T_{\max } \dagger}$ & $\begin{array}{l}6 \cdot 22(0 \cdot 13) \\
89(13)[4]\end{array}$ & $\begin{array}{l}6 \cdot 22(0 \cdot 13) \\
78,91[2]\end{array}$ & $\begin{array}{l}6.04(0 \cdot 10) \\
176(68)[3]\end{array}$ \\
\hline $\mathrm{LTC}_{4}$ & $\frac{-\log \mathrm{EC}_{50} \mathrm{~T}_{\max } \dagger}{}$ & $\begin{array}{l}8 \cdot 24(0.08) \\
53,79[2]\end{array}$ & $\begin{array}{l}8.00(0.06) \\
18[1]\end{array}$ & $\begin{array}{l}7.89(0.08) \\
40(12)[3]\end{array}$ \\
\hline
\end{tabular}

*Mean (SEM) of 30 measurements.

†Expressed in $\mathrm{mg}$ isometric force per $\mathrm{mg}$ dry tissue weight. The number of observations is indicated in square brackets; only the firso concentration-response curve for each strip is included (see under "Methods"). Mean (SEM) values are given for three observations or more; otherwise individual values are given.
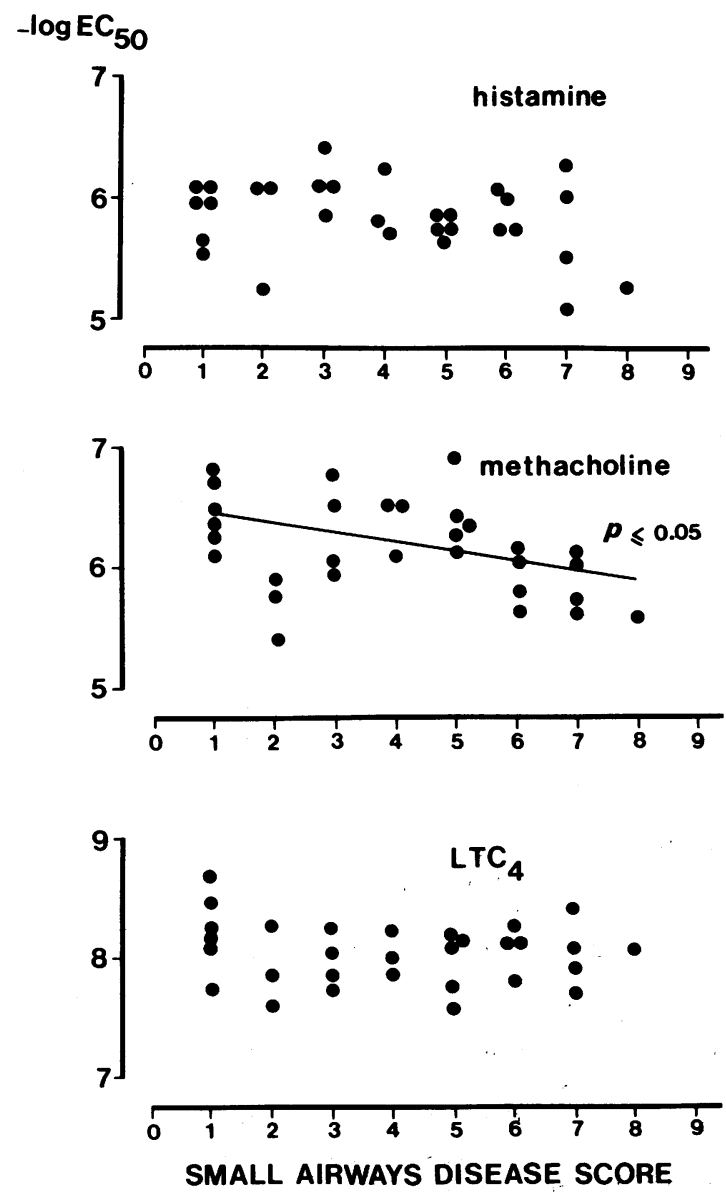

Fig 2 Relation between - $\log E C_{50}$ values for histamine, methacholine, and $\mathrm{LTC}_{4}$ and total small airways disease scores for 30 bronchiolar strips from 30 patients with and t. . without chronic bronchitis.
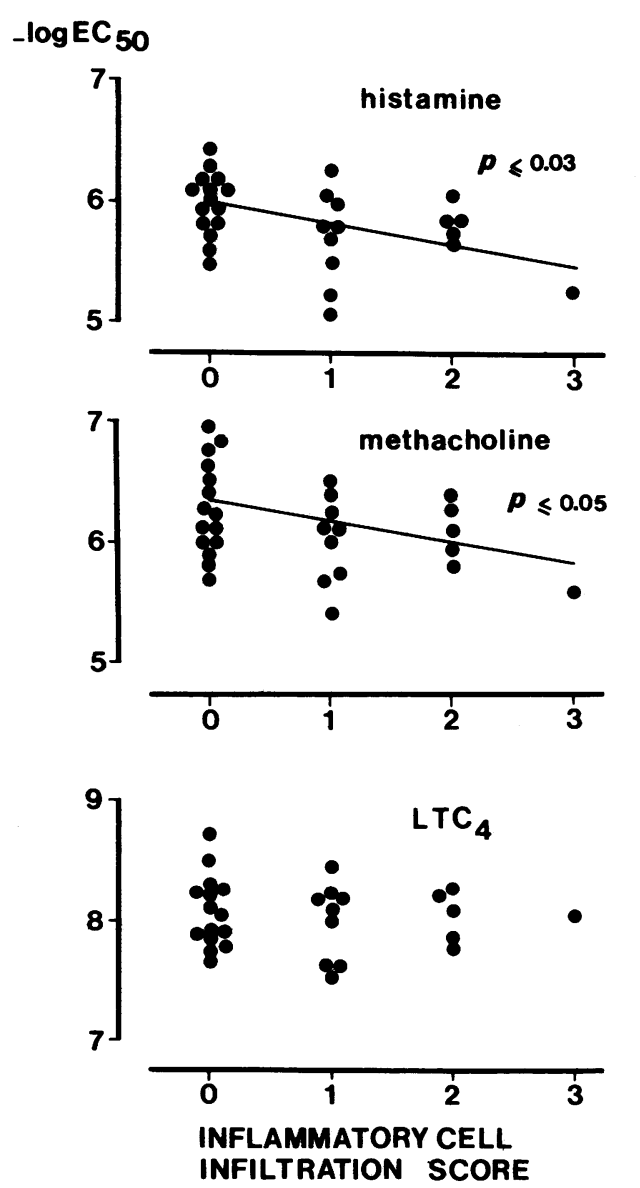

Fig 3 Relation between - $\log E C_{50}$ values for histamine, methacholine, and $\mathrm{LTC}_{4}$ and inflammatory cell infiltration scores for 30 bronchiolar strips from 30 patients with and without chronic bronchitis. 
further processing of the bronchiolar strips altered smooth muscle function, conceivably by removing humoral factors or inflammatory cells. We did not repeat the histological examination after the challenge experiments, but preliminary investigation did not show any deleterious effects of storage or organ bath studies on the histological appearance of the airways. Moreover, we and others have shown that prolonged storage in cold buffer does not affect in vitro human airway smooth muscle responsiveness to histamine or methacholine. ${ }^{1114}$ It therefore seems unlikely-though the possibility cannot be excluded-that we have missed an effect of inflammation on smooth muscle function as a result of factors relating to tissue processing.

In the dog, ozone induced acute airway inflammation is associated with airway hyperresponsiveness, ${ }^{415}$ and this has been linked to granulocyte infiltration in the airway wall. In the guinea pig, ozone and cigarette smoke also produce acute airway inflammation and hyperresponsiveness, ${ }^{16}{ }^{17}$ though in this model hyperresponsiveness preceded cellular infiltration and the granulocytes persisted longer than the increased responsiveness. Possibly in chronic inflammation airway hyperresponsiveness does not persist if inflammatory cells continue to be present after the acute phase, and this would explain the contradictory results in human and animal airways regarding inflammation and responsiveness.

Our findings are in agreement with the clinical observation that patients with severe chronic nonasthmatic airway inflammation, such as occurs in cystic fibrosis or bronchiectasis, usually have only mild bronchial hyperresponsiveness or none at all, despite large numbers of leucocytes in their airways. Our results confirm and extend the findings of Armour et al, who did not find an association between inflammation and in vitro responsiveness of human airways to histamine and carbachol in a smaller group of patients. ${ }^{78}$

In the present study and in other reports on in vivo and in vitro responsiveness of human airways there has been only a weak correlation or none between the amount of airway smooth muscle and airway responsiveness. ${ }^{371819}$ This suggests that not only the amount but also the intrinsic properties of airway smooth muscle may determine airway responsiveness. In addition, the arrangement of smooth muscle, rather than its amount, is likely to be responsible for a large part of the high intrinsic variability of $T_{\max }$ in spirally cut strips. Mullen et al found that in nonasthmatic smokers inflammation of membranous bronchioles correlated with in vivo airway responsiveness. ${ }^{3}$ These authors also found a relation between bronchiolar inflammation and in vivo airway calibre, but the effects of these factors on airway responsiveness seemed to be independent. ${ }^{3}$ Our present findings do not support a direct effect of inflammation on bronchiolar smooth muscle function. It remains possible, however, that peripheral airway inflammation modulates airway responsiveness in vivo by other mechanisms - for example, by altering autonomic regulation processes. Furthermore, our results do not exclude an effect of inflammation on smooth muscle function in central airways. Such an effect seems unlikely, however, as in the study by Mullen et al no relationship was found between inflammatory changes in central airways and in vivo bronchial responsiveness. ${ }^{3}$ In the tissues we studied we found no small airway disease scores above eight. Although our results do not point in this direction, we cannot exclude the possibility that smooth muscle sensitivity or contractility would have been abnormal in bronchioles with a higher score. This seems very unlikely, however, because severe small airway disease is not a characteristic of subjects with a greatly increased in vivo airway responsiveness. ${ }^{3}$

We, like others, ${ }^{20}$ found small airway disease to a variable degree in lungs from both patients with and patients without chronic bronchitis and airflow obstruction, with a large overlap. This indicates that histological signs of small airways disease are not specific for chronic bronchitis, and may occur in otherwise healthy, non-smoking symptomless subjects with normal lung function. This, together with the finding that small airway inflammation had no relation to in vitro small airway smooth muscle function, suggests that airway hyperresponsiveness in chronic bronchitis is not due to a direct effect of chronic inflammation on airway smooth muscle function.

Our present findings do not exclude the possibility that the inflammation may potentiate the mechanisms that underly airway hyperresponsiveness in asthma. We have recently reported increased contractility in isolated airways showing eosinophilic infiltration of the bronchial mucosa and smooth muscle hypertrophy from an asthmatic subject. ${ }^{21}$ Airway hyperresponsiveness in asthma and chronic bronchitis has different characteristics, however, and may have a different pathogenesis. ${ }^{22}$

More studies are needed to establish to what extent airway inflammation or alternative mechanisms, such as mucosal oedema, changes in central airways, potentiation of local or central nervous reflexes, or other abnormalities in neural control, contribute to the pathogenesis of airway hyperresponsiveness in chronic bronchitis and asthma.

We wish to thank the medical staff of the Pulmonology Department, the Thorax Centre, and the Pathology Department of the Academic Hospital, 
Rotterdam, for their help, and Dr Dick Tibboel (Department of Surgery, Sophia Children's Hospital) and Dr Luuk Willems (Pathology Department Academic Hospital, Leiden) for their expert advice on the histological scoring system.

\section{References}

1 Chung KF. Role of inflammation in the hyperreactivity of the airways in asthma. Thorax 1986;41:657-62

2 Boushey HA, Holtzman MJ. Experimental airway inflammation and hyperreactivity. Searching for cells and mediators. Am Rev Respir Dis 1985;131:312-3.

3 Mullen JBM, Wiggs BR, Wright JL, Hogg JC, Pare PD. Non-specific airway reactivity in cigarette smokers. Relationship to airway pathology and baseline lung function. Am Rev Respir Dis 1986;133:120-5.

4 Holtzman MJ, Fabbri LM, O'Byrne PM, el al. Importance of airway inflammation for hyperresponsiveness induced by ozone. Am Rev Respir Dis 1983;127: 686-90.

5 Empey DW, Laitinen LA, Jacobs L, Gold WM, Nadel JA. Mechanisms of bronchial hyperreactivity in normal subjects after upper respiratory tract infection. Am Rev Respir Dis 1976;113:131-9.

6 De Jongste JC, Mons H, Block R, Bonta IL, Frederiksz AP, Kerrebijn KF. Increased in vitro histamine responses in human small airway smooth muscle from patients with chronic obstructive pulmonary disease. Am Rev Respir Dis 1987;135:549-53.

7 Armour CL, Black JL, Berend N, Woolcock AJ. The relationship between bronchial hyperresponsiveness to methacholine and airway smooth muscle structure and reactivity. Repir Physiol 1984;58:223-33.

8 Armour CL, Black JL, Berend N. The lung parenchymal strip as a model of peripheral airway responsiveness. Bull Eur Physiopathol Respir 1985;21:545-9.

9 Medical Research Council. Definition and classification of chronic bronchitis for clinical and epidemiological purposes. Lancet 1965;i:775-779.

10 Bogaard JM, Verheijen-Breemhaar L, Kroon TAJ, et al. Histamine log (dose)-response curves in asthmatics. Respiration 1985;47:278-84.
11 De Jongste JC, Van Strik R, Bonta IL, Kerrebijn KFO Measurement of human small airway smooth muscle function in vitro with the bronchiolar strip prepara(s) tion. J Pharmacol Methods 1985;14:111-8.

12 De Jongste JC, Mons H, Van Strik R, Bonta IL, Ker rebijn KF. Human small airway smooth musclø responses in vitro: actions and interactions of meth $\overrightarrow{5}$ acholine, histamine and leukotriene $\mathrm{C}_{4}$. Eur J Pharmdicol 1986;125:29-35.

13 Cosio M, Ghezzo H, Hogg JC, et al. The relations between structural changes in small airways an pulmonary function tests. $N$ Engl $J$ Meq 1977;298:1277-81.

14 Brink C, Grimaud C, Guillot C, Orehek J. The interaction between indomethacin and contractile ageniso on human isolated airway muscle. Br $J$ Pharmaced 1980;69:383-8.

15 Fabbri LM, Aizawa H, Alpert SE, et al. Airway hyper?responsiveness and changes in cell counts in bronchoz alveolar lavage after ozone exposure in dogs. $A m$ Re⿻ Respir Dis 1984;129:288-91.

16 Hulbert WM, McLean T, Hogg JC. The effect of acuege airway inflammation on bronchial reactivity in guinea pigs. Am Rev Respir Dis 1985;132:7-11.

17 Murlas CG, Roum JH. Sequence of pathologic change in the airway mucosa of guinea pigs during ozoneinduced bronchial hyperreactivity. Am Rev Respir Dig 1985;131:314-20.

18 Armour CL, Lazar NM, Schellenberg RR, et al. A com? parison of in vivo and in vitro human airway reactivita to histamine Am Rev Respir Dis 1984;129:907-10.

19 Roberts JA, Rodger IW, Thomson NC. Human in vitr@ bronchial smooth muscle responses to leukotriene $\mathrm{D}_{\overrightarrow{\mathrm{S}}}$ in relation to the quantity of muscle. Thora

1986;41:734.
20 Mullen JBM, Wright JL, Wiggs BR, Paré, Hogg J薑 Reassessment of inflammation of airways in chronis bronchitis. Br Med J 1985;291:1235-9.

21 De Jongste JC, Mons H, Bonta IL, Kerrebijn KF. W vitro responses of airways from an asthmatic patien Eur J Respir Dis 1987;71:23-9.

22 Yan K, Salome CM, Woolcock AJ. Prevalence and nature of bronchial hyperresponsiveness in subjects with chronic obstructive pulmonary disease. Am Re Respir Dis 1985;132:25-9. 